\title{
Long Delay Free Recall (CVLT-C)
}

National Cancer Institute

\section{Source}

National Cancer Institute. Long Delay Free Recall (CVLT-C). NCI Thesaurus. Code C120397.

The fourth part of the California Verbal Learning Test for Children. After a 20-minute non-verbal task, the child is asked to recall as many words as he or she can from List A. 